\title{
Pengaruh Social Media Addiction terhadap Depresi dengan Social Comparison Sebagai Variabel Moderator pada Pengguna Instagram
}

\author{
Jessica Noviana Onggono ${ }^{* 1}$ \\ Fakultas Psikologi Universitas Ciputra Surabaya \\ Stefani Virlia \\ Fakultas Psikologi Universitas Ciputra Surabaya
}

\begin{abstract}
The purpose of this study is to determine whether social comparison can moderate the influence between social media addiction to depression in Instagram user. Hypotesis of this study is social comparison can moderate the influence of social media addiction toward depression in Instagram users. This study is a quantitative research and data are collected using depression scale "Beck Depression Inventory Second Edition", social media modified scale "Bergen Facebook Addiction Scale”, and social comparison scale "Iowa-Netherlands Comparison Orientation Measure". The scales were spread across 98 subjects. The result show that social comparison can not moderate the influence of social media addiction towards depression $\left(R^{2}=\right.$ 0.045; $p=0.912 ; p>0.05)$, because social comparison are not always negative, so social comparison did not strengthen or weaken the influence of social media addiction toward depression in Instagram users.
\end{abstract}

Keywords: depression, social media addiction, social comparison, university students, instagram

\begin{abstract}
Abstrak. Tujuan dari penelitian ini adalah untuk mengetahui apakah social comparison dapat memoderatori pengaruh antara social media addiction terhadap depresi pada pengguna Instagram. Hipotesis pada penelitian ini adalah social comparison dapat memoderatori pengaruh social media addiction terhadap depresi pada pengguna Instagram. Penelitian ini merupakan penelitian kuantitatif dengan pengumpulan data menggunakan skala depresi "Beck Depression Inventory Second Edition”, skala social media addiction "Bergen Facebook Addiction Scale" yang dimodifikasi, dan skala social comparison "Iowa-Netherlands Comparison Orientation Measure". Skala disebarkan kepada 98 subjek penelitian. Hasil penelitian menunjukkan bahwa social comparison tidak dapat memoderatori pengaruh antara social media addiction terhadap depresi $\left(R^{2}=0.045 ; p\right.$ $=0.912 ; p>0.05)$, dikarenakan social comparison tidak selalu negatif, sehingga social comparison tidak memperkuat atau memperlemah pengaruh antara social media addiction terhadap depresi pada pengguna Instagram.
\end{abstract}

Kata kunci: depresi, social media addiction, social comparison, mahasiswa, instagram

\footnotetext{
${ }^{1}$ Korespondensi: Jessica Noviana Onggono . Fakultas Psikologi Universitas Ciputra Surabaya, UC Town, Citraland, Surabaya, 60219. Email: jessicanoviana14@gmail.com
} 
Saat ini media sosial sudah banyak digunakan oleh banyak orang, salah satunya adalah Instagram. Menurut NapoleonCat (2020), pengguna Instagram terbanyak di Indonesia adalah orang-orang yang berusia 18-24 tahun dengan persentase $37.5 \%$, dan pada usia tersebut, individu sedang memasuki masa beranjak dewasa atau emerging adulthood, yaitu individu yang berusia 18 sampai 25 tahun (Arnett dalam Santrock, 2013). Pada usia tersebut, banyak anak muda yang sedang melanjutkan pendidikan tinggi (Arnett, 2014), sehingga dapat disimpulkan bahwa banyak pengguna Instagram di Indonesia yang merupakan mahasiswa. Banyaknya pengguna Instagram tidak lepas dari banyaknya fitur-fitur yang dimiliki oleh Instagram, yaitu fitur like, comment, hashtag, serta membagikan foto dan video ke satu pengguna ke pengguna lain (Sosiawan \& Wibowo, 2018; Sheldon \& Bryant, 2016). Alasan menggunakan Instagram pun bermacam-macam, dimulai dari untuk berbisnis, untuk hiburan, mencari informasi, hingga untuk aktualisasi diri (Alfindra \& Yahya, 2017).

Penggunaan Instagram saat ini yang digunakan oleh anak muda dapat memberikan dampak positif bagi penggunanya, yaitu adanya fitur menarik, bisa mendapatkan informasi, mendapatkan hiburan dari berbagai foto dan video yang dibagikan pengguna, untuk aktualisasi diri, mendapatkan penghasilan dari Instagram, dan dapat terkoneksi dengan pengguna lainnya. Oleh karena itu, peneliti menemukan kesenjangan, yaitu hingga saat ini masih belum ada penelitian mengenai dampak negatif Instagram yang berhubungan dengan kesehatan mental, terutama depresi. Hal ini juga dibuktikan dari wawancara peneliti dengan salah satu subjek, yang mengatakan bahwa Instagram membuat individu merasa insecure, merasa tidak bisa, sehingga menimbulkan rasa rendah diri dan stress, dan mengarah ke depresi. Hal ini juga didukung dari hasil survei milik Royal Society for Public
Health (RSPH) terhadap kaum muda berusia 14 sampai 24 tahun di Inggris, bahwa Instagram sering membuat kaum muda merasa depresi, cemas, kesepian, mengalami bullying, memiliki masalah pada citra tubuh, dan mengalami Fear of Missing Out (FoMO) (Wardani, 2017; Gaol, Mutiara, Saraswati, Rahmadini, \& Hilmah, 2018). Menurut Beck dan Alford (2009), depresi merupakan individu yang mengalami perubahan suasana hati; memiliki konsep diri negatif; menyalahkan dirinya sendiri; memiliki keinginan reaktif dan menghukum diri sendiri; mengalami perubahan nafsu makan dan pola tidur; kehilangan libido; dan mengalami perubahan tingkat aktivitas. Depresi terdiri dari dua aspek yaitu somatic-affective dan cognitive. Aspek somatic-affective merupakan depresi yang terdiri dari gejala somatik dan gejala afektif, sedangkan aspek cognitive merupakan depresi yang terdiri dari gejala psikologis (Beck, Steer, \& Brown, dalam Beck, Steer, Ball, \& Ranieri, 1999).

Pada depresi di Instagram, salah satu faktor yang dapat mempengaruhi depresi adalah social media addiction. Hal ini didukung dengan pernyataan dari, Trub, dan Rosenthal (2015), bahwa penggunaan Instagram yang berlebihan bisa mengarah ke depresi. Selain itu, penggunaan media sosial yang berlebihan bisa mengarah ke adiksi (Sumaryanti, Azizah, Diantina, \& Nawangsih, 2020). Social media addiction sendiri merupakan perasaan khawatir dari individu yang berlebihan ketika menggunakan media sosial, dengan motivasi yang tidak terkendali dalam berperilaku, dan menghabiskan banyak waktunya untuk menggunakan media sosial, sehingga merusak aspek kehidupan penting lainnya (Andreassen \& Pallesen, dalam Andreassen, Pallesen, \& Griffith, 2017). Social media addiction terdiri dari enam aspek, yaitu salience (media sosial mendominasi pikiran dan perilaku individu), mood modification (menggunakan media sosial bisa 
mempengaruhi mood), tolerance (meningkatkan penggunaan media sosial untuk mencapai efek sebelumnya), withdrawal (perasaan tidak nyaman ketika tidak menggunakan media sosial atau tibatiba mengurangi penggunaan media sosial), conflict (media sosial menyebabkan konflik di hubungan individu dengan orang lain, pekerjaan/pendidikan, dan aktivitas lainnya), dan relapse (kembali ke pola sebelumnya ketika kembali setelah berhenti menggunakan media sosial) (Andreassen, Torsheim, Brunborg, \& Pallesen, 2012).

Adanya social media addiction membuat individu menghabiskan waktunya secara online, dan pengalaman positif yang didapatkan dari media sosial membuat individu terus menerus menggunakan internet (Glaser, Liu, Hakim, Vilar, \& Zhang, 2018). Kemudian, ketika individu banyak menghabiskan waktunya untuk menggunakan media sosial secara berlebihan, individu akan semakin jauh dari kehidupan nyata, sehingga waktu individu bersama dengan keluarga dan teman-teman yang ada di dunia nyata akan tergantikan dengan media sosial, sehingga memunculkan mood negatif seperti kesepian dan depresi (Kraut dkk, dalam Li dkk, 2018).

Dari variabel depresi dan social media addiction, peneliti menduga terdapat variabel lain yang bisa memoderatori pengaruh antara social media addiction terhadap depresi, yang dibuktikan dari hasil wawancara peneliti dengan subjek, yang mengatakan bahwa subjek cenderung membandingkan dirinya dengan orang lain yang ada di Instagram, sehingga peneliti menyimpulkan bahwa social comparison dapat memoderatori pengaruh social media addiction terhadap depresi. Social comparison sendiri merupakan bagaimana individu melakukan evaluasi terhadap opini dan kemampuan dirinya dengan orang lain (Festinger, 1954). Social comparison terdiri dari dua aspek, yang pertama adalah ability, yang mencerminkan ketertarikan individu dengan hal-hal yang berkaitan dengan perbandingan kinerja atau kemampuan dengan orang lain, dan aspek opinion, yang mencerminkan ketertarikan individu pada perbandingan yang berdasarkan dari pendapat orang lain (Gibbons \& Buunk, 1999).

Pada penelitian sebelumnya, ditemukan bahwa penggunaan Facebook dapat mempengaruhi persepsi penggunanya terhadap pengguna lain, dan menurut Donnelly dan Kuss (2016), temuan ini dapat diterapkan di Instagram. Menurut Donnelly dan Kuss (2016), individu yang menghabiskan waktunya untuk membuka Instagram dapat menimbulkan keyakinan yang kuat bahwa pengguna lain memiliki kehidupan yang lebih bahagia dari dirinya, dan keyakinan bisa menjadi lebih buruk ketika individu terhubung secara online dengan pengguna lain (misalnya orang yang tidak dikenal, selebriti, dan publik figur), yang menyebabkan individu mengalami bias dan melakukan social comparison. Kemudian, menurut penelitian dari Budury, Fitriasari, dan Khamida (2019), depresi, kecemasan, dan stres yang muncul dari media sosial dikarenakan media sosial dapat memfasilitasi penggunanya untuk membandingkan dirinya dengan orang lain. Oleh karena itu, dapat disimpulkan bahwa mahasiswa yang mengalami social media addiction ketika menggunakan Instagram, dan ditambah dengan hadirnya social comparison dapat membuat mahasiswa membandingkan dirinya, sehingga muncul persepsi yang bias dari diri mahasiswa dan memperkuat terjadinya depresi pada mahasiswa pengguna Instagram.

Penelitian ini memiliki keunikan tersendiri. Pada penelitian sebelumnya, belum ada yang menguji mengenai ketiga variabel tersebut, belum banyak penelitian mengenai adiksi Instagram pada depresi di Indonesia, dan belum banyak penelitian 
yang berfokus pada media sosial Instagram saja. Penelitian ini bertujuan untuk mengetahui apakah social comparison dapat memoderatori pengaruh social media addiction terhadap depresi pada mahasiswa pengguna Instagram. Hipotesis mayor pada penelitian ini adalah social comparison dapat memoderatori pengaruh antara social media addiction terhadap depresi pada mahasiswa pengguna Instagram, serta terdapat dua hipotesis minor pada penelitian ini, yaitu pertama, terdapat pengaruh antara social media addiction terhadap depresi pada mahasiswa pengguna Instagram, dan kedua, terdapat pengaruh antara social comparison sebagai variabel moderator terhadap depresi pada mahasiswa pengguna Instagram. Penelitian ini diharapkan dapat memberikan manfaat untuk ilmu psikologi klinis, perkembangan, dan psikologi sosial, untuk mahasiswa pengguna Instagram, significant others dari mahasiswa, dan konselor terkait dengan depresi, social media addiction pada Instagram, dan social comparison.

\section{METODE}

Penelitian ini menggunakan pendekatan kuantitatif dengan desain penelitian korelasional. Variabel bebas yang digunakan pada penelitian ini adalah social media addiction. Semakin tinggi total skor pada skala social media addiction, maka semakin tinggi frekuensi individu dalam melakukan social media addiction. Sebaliknya, semakin total skor pada skala social media addiction, maka semakin rendah juga frekuensi social media addiction pada individu. Variabel terikat yang digunakan pada penelitian ini adalah depresi. Semakin tinggi total skor dari skala depresi, maka tingkat depresi individu semakin tinggi, sedangkan semakin rendah total skor dari skala depresi, maka semakin rendah juga tingkat depresi dari individu. Variabel moderator yang digunakan pada penelitian ini adalah social comparison. Semakin tinggi total skor dari skala social comparison, maka semakin tinggi juga tendensi individu untuk membandingkan dirinya. Sebaliknya, semakin rendah total skor pada skala social comparison, semakin rendah tendensi individu untuk membandingkan dirinya.

Penelitian ini memakai metode survei sebagai instrumen penelitian dan peneliti mengumpulkan data menggunakan skala. Skala yang digunakan adalah Beck Depression Inventory Second Edition (BDI-II) untuk mengukur depresi yang dibuat oleh Beck, Steer, dan Brown (1996), skala Bergen Facebook Addiction Scale (BFAS) untuk mengukur social media addiction yang dibuat oleh Andreassen et al. (2012) dan telah dimodifikasi sesuai dengan subjek penelitian, yaitu mahasiswa pengguna Instagram, dan skala IowaNetherlands Comparison Orientation Measure (INCOM) yang dibuat oleh Gibbons \& Buunk (1999) untuk mengukur social comparison.

Skala BDI-II terdiri dari 21 aitem. Pada penelitian ini, skala ini memiliki reliabilitas Cronbach Alpha $=0.792$ pada aspek somative-affective dan Cronbach Alpha $=0.799$ pada aspek cognitive. Skala BFAS terdiri dari 18 aitem. Hasil uji reliabilitas pada skala ini yaitu Cronbach Alpha $=0.714$ pada aspek salience, Cronbach Alpha $=0.840$ pada aspek mood modification, Cronbach Alpha $=0.854$ pada aspek tolerance, Cronbach Alpha $=$ 0.785 pada aspek withdrawal, Cronbach Alpha $=0.807$ pada aspek conflict, dan Cronbach Alpha $=0.815$ pada aspek relapse. Kemudian, skala INCOM terdiri dari 11 aitem. Berdasarkan hasil uji reliabilitas, aspek ability memiliki Cronbach Alpha $=0.808$ dan aspek opinion memiliki Cronbach Alpha $=0.769$, dan aitem nomor 11 harus dikeluarkan karena memiliki Corrected Item Total Correlation (CITC) di bawah 0.3, sehingga pada penelitian ini, terdapat 10 aitem skala INCOM yang digunakan. 
Pada pengerjaan skala BDI-II, subjek diminta untuk menilai dan merasakan gejala depresi pada dirinya dimulai dari angka 0 (tidak parah) hingga angka 3 (sangat parah). Semakin subjek menjawab 0 , maka subjek semakin tidak menunjukkan gejala depresi, dan semakin subjek menjawab ke angka 3, maka semakin parah gejala depresi pada subjek. Sedangkan pada skala BFAS dan INCOM, subjek diminta untuk memilih dari angka 1 sampai dengan angka 5 dari setiap aitem. Pada skala BFAS, semakin subjek memilih angka yang tinggi, maka semakin sering subjek melakukan pernyataan pada skala, dan semakin subjek memilih angka yang rendah, maka semakin jarang subjek melakukan pernyataan pada skala. Sedangkan pada skala INCOM, semakin tinggi subjek memilih angka, maka semakin setuju subjek terhadap pernyataan pada skala. Sebaliknya, semakin rendah subjek memilih angka, maka semakin tidak setuju subjek terhadap pernyataan pada skala.

Teknik pengambilan sampel yang digunakan di penelitian ini adalah menggunakan purposive sampling, yaitu peneliti menentukan kriteria untuk mendapatkan sampel, yaitu laki-laki atau perempuan berusia 18-25 tahun, merupakan mahasiswa aktif yang berkuliah di Surabaya, dan merupakan pengguna Instagram. Subjek pada penelitian ini adalah 98 orang, dengan jumlah 36 subjek adalah laki-laki, dan 62 subjek perempuan.

Penelitian ini menggunakan program JASP versi 14.0.0. Uji hipotesis mayor menggunakan Moderated Regression Analysis (MRA), dan menggunakan analisis regresi linear untuk kedua hipotesis minor.

\section{HASIL DAN DISKUSI}

Berdasarkan uji hipotesis yang dilakukan, diketahui bahwa social comparison tidak dapat memoderatori pengaruh social media addiction terhadap depresi $\left(\mathrm{R}^{2}=\right.$ $0.045 ; \mathrm{p}=0.912 ; \mathrm{p}>0.05)$. Artinya, hipotesis pada penelitian ini ditolak.

Adanya social comparison yang tidak dapat memoderatori pengaruh social media addiction terhadap depresi kemungkinan disebabkan karena mahasiswa tidak selalu melakukan social comparison yang negatif ketika menggunakan Instagram, sehingga mahasiswa tidak semakin depresi. Ada kemungkinan bahwa mahasiswa melakukan social comparison di Instagram karena dirinya ingin melakukan kompetisi dengan pengguna lain, sehingga pada penelitian ini, social comparison tidak dapat memoderatori pengaruh social media addiction dan depresi. Ditambah lagi, menurut Garcia, Reese, dan Tor (2019), dasar dari social comparison sangat dekat kaitannya dengan perilaku kompetitif.

Sebelum mahasiswa melakukan social comparison di Instagram, mahasiswa akan menentukan tujuannya, yaitu untuk pengembangan dirinya. Hal ini didukung dengan argumen bahwa individu yang sudah memiliki tujuan untuk mengembangkan dirinya menjadi lebih baik memiliki motivasi untuk melakukan social comparison yang dapat memfasilitasi terjadinya perilaku kompetitif pada individu, dan individu yang memiliki tujuan untuk menjadi lebih baik akan termotivasi untuk bekerja lebih baik di tugas-tugasnya (Darnon, Dompnier, \& Poortvliet, 2012; Summers, Scallert, \& Ritter, 2003).

Kemudian, selama individu berkompetisi, terdapat faktor-faktor yang membuat individu melakukan social comparison, yang bisa meningkatkan intensitas perilaku 
kompetitif, dan faktor tersebut bisa berasal dari individu itu sendiri dan faktor situasional (Garcia dkk, 2019). Pada social media addiction terhadap depresi, social media addiction tidak termasuk kedalam faktor individu maupun faktor situasional karena perkembangan media sosial yang mendukung banyak minat individu, sehingga meningkatkan perilaku adiksi untuk pemenuhan kebutuhannya (Dailey, Howard, Roming, Ceballos, \& Grimes, 2020). Oleh karena itu, dapat disimpulkan bahwa social media addiction berperan sebagai pemenuhan kebutuhan dari mahasiswa pengguna Instagram, yang dapat membuat mahasiswa membandingkan dirinya, menghasilkan perilaku kompetitif.

Setelah perilaku kompetitif selesai, hasil yang dikeluarkan akan berbeda, tergantung dari dua jenis social comparison yang ada, yaitu downward social comparison dan upward social comparison. Downward social comparison terjadi ketika individu membandingkan dirinya dengan orang lain yang lebih buruk dari dirinya (Suls, Martin, \& Wheeler, 2002), sedangkan upward social comparison terjadi ketika individu membandingkan dirinya dengan orang lain yang memiliki kedudukan yang lebih tinggi dari dirinya (Wheeler, dalam Wang, Wang, Gaskin, \& Hawk, 2017). Berdasarkan dua jenis social comparison tersebut, diketahui bahwa downward social comparison berkorelasi dengan kepuasan kerja (Brown, Ferris, Heller \& Keeping, 2007), sehingga dapat disimpulkan bahwa mahasiswa yang melakukan downward social comparison di Instagram dengan pengguna lain akan merasa puas dengan kinerjanya karena mahasiswa merasa ternyata dirinya masih lebih baik dibandingkan dengan pengguna lain. Pada upward social comparison, diketahui bahwa upward social comparison dapat memenuhi tiga tujuan dari social comparison, yaitu untuk evaluasi diri, perbaikan diri, dan peningkatan diri. Selain itu, menurut Meier,
Gilbert, Borner, dan Possler (2020), upward social comparison membuat pengguna lain membandingkan dirinya dengan pengguna lain yang lebih baik dari dirinya, ditambah lagi dengan Instagram bisa memfasilitasi individu untuk membandingkan dirinya. Setelah itu, individu akan merasa iri dan menjadikan pengguna lain sebagai role modelnya, dan individu menjadi terinspirasi untuk menjadi lebih baik lagi. Ketika individu merasa terinspirasi, akan muncul perasaan positif yang bisa meningkatkan well-being dari individu. Artinya, social comparison bisa membuat mahasiswa mengetahui dan mengembangkan potensinya menjadi lebih baik lagi dan meningkatkan well-being, bukan menjadi depresi.

Selain itu, peneliti juga melakukan uji regresi linear pada social media addiction terhadap depresi, dan ditemukan bahwa social media addiction tidak memiliki pengaruh terhadap depresi $\left(\mathrm{R}^{2}=0.031 ; \mathrm{p}=\right.$ $0.081 ; \mathrm{p}>0.05)$. Selain itu, peneliti melakukan uji regresi linear pada social comparison terhadap depresi, dan ditemukan bahwa social comparison juga tidak memiliki pengaruh terhadap depresi $\left(\mathrm{R}^{2}=0.027 ; \mathrm{p}=0.105 ; \mathrm{p}>0.05\right)$.

Tidak adanya pengaruh social media addiction terhadap depresi bisa saja disebabkan karena sosial media dan depresi merupakan hubungan dan kompleks (Baker \& Algorta, 2016). Selain itu, mahasiswa yang kecanduan dalam menggunakan Instagram bukan disebabkan karena ada peningkatan frekuensi mahasiswa dalam menggunakan instagram, namun lebih cenderung ke bagaimana pengalaman yang didapatkan mahasiswa ketika menggunakan Instagram. Hal ini didukung oleh argumen bahwa pengalaman yang didapatkan dari media sosial bisa menjadi prediktor depresi dibandingkan dengan waktu yang dihabiskan di media sosial, dan waktu yang dihabiskan ketika menggunakan media sosial merupakan hasil dari 
pengalaman yang dialami individu (Choukas-Bradley dkk, 2019; Wu, 2019). Selain itu, tidak adanya pengaruh social media addiction terhadap depresi dapat disebabkan karena Instagram dapat dijadikan sebagai sarana untuk menghilangkan hal-hal negatif yang dialami mahasiswa pengguna Instagram, sesuai dengan penelitian dari Baker dan Algorta (2016), bahwa individu yang kecanduan media sosial disebabkan karena individu menggunakan media sosial sebagai alat untuk coping stress pada masalah mental yang dialami.

Selanjutnya, tidak adanya pengaruh social comparison terhadap depresi juga dapat disebabkan karena lemahnya hubungan antara social comparison dengan depresi. Selain itu, tidak semua individu melakukan social comparison secara negatif, sehingga hasil yang muncul ketika social comparison dilakukan bukanlah depresi, melainkan hal lain yang bersifat positif bagi mahasiswa. Argumen ini didukung dengan penelitian yang dilakukan Brown dkk. (2007), bahwa downward social comparison dapat membuat individu puas dengan pekerjaannya, dan upward social comparison dapat membuat individu menjadi terinspirasi untuk melakukan yang terbaik sehingga meningkatkan wellbeingnya (Meier dkk, 2020).

Selain itu, terdapat beberapa faktor yang mempengaruhi depresi ketika menggunakan Instagram, diantaranya adalah yaitu pengalaman ketika menggunakan Instagram, perasaan neurotic, rasa kesepian, extraversion, agreeableness, consciousness, body surveillance, perbuatan cyberbullying, Fear of Missing Out (FoMO), dan selfesteem (Kokkinos \& Saripanidis, 2017; Zhang, 2017; Choukas-Bradley dkk, 2019; Wu, 2019; Kartol \& Gundogan, 2020).

Peneliti juga melakukan tabulasi silang sebagai hasil tambahan. Pada tabulasi silang, ditemukan bahwa durasi menggunakan Instagram memiliki hubungan dengan social media addiction. Semakin bertambah durasi penggunaan Instagram, maka tingkat social media addiction juga semakin tinggi. Hal ini sesuai dengan penelitian yang dilakukan oleh Kircaburun \& Griffiths (2018), bahwa waktu yang digunakan untuk menggunakan internet dapat memprediksi adiksi pada Instagram. Selain itu, ada kemungkinan mahasiswa pengguna Instagram memiliki kontrol diri yang rendah, sehingga mahasiswa menjadi kurang mampu untuk berhenti ketika menggunakan Instagram, dan mereka menggunakan Instagram dalam waktu yang lama. Hal ini sesuai dengan penelitian dari Muna dan Astuti (2014), bahwa kontrol diri yang rendah bisa membuat individu menjadi kecanduan ketika menggunakan media sosial.

\section{SIMPULAN}

Berdasarkan penelitian yang dilakukan, dapat disimpulkan bahwa social comparison tidak dapat memoderatori pengaruh antara social media addiction dan depresi pada mahasiswa pengguna Instagram $\left(\mathrm{R}^{2}=0.027 ; \mathrm{p}=0.912 ; \mathrm{p}>\right.$ $0.05)$. Social media addiction juga tidak mempengaruhi depresi $\left(\mathrm{R}^{2}=0.031 ; \mathrm{p}=\right.$ $0.081 ; \mathrm{p}>0.05)$, dan social comparison tidak mempengaruhi depresi $\left(\mathrm{R}^{2}=0.027\right.$; $\mathrm{p}=0.105 ; \mathrm{p}>0.05)$. Faktor lain yang diduga dapat mempengaruhi depresi dalam penggunaan Instagram adalah FoMO, selfesteem, kesepian, perasaan neurotic, extraversion, agreeableness, consciousness, cyberbullying, body surveillance, serta pengalaman yang didapatkan dari menggunakan media sosial.

Oleh karena itu, peneliti menyarankan pada mahasiswa pengguna Instagram untuk membatasi penggunaan Instagram agar tidak mendapatkan dampak negatif yang berlebihan. Peneliti juga menyarankan pada significant others dari 
mahasiswa pengguna Instagram untuk memberikan dukungan sosial bagi mahasiswa yang depresi ketika menggunakan Instagram atau mendapatkan dampak negatif lainnya karena penggunaan Instagram yang berlebihan. Peneliti juga menyarankan konselor untuk mencari gambaran mengenai individu di tahap emerging adulthood yang mengalami depresi, terutama yang disebabkan oleh penggunaan Instagram.

Penelitian ini masih memiliki keterbatasan. Pertama, subjek penelitian yang cenderung kurang banyak dan pengambilan data yang menggunakan non-probability sampling, sehingga data yang terkumpul terfokus pada kelompok tertentu. Oleh karena itu, peneliti menyarankan bagi peneliti selanjutnya untuk mencari faktor lain yang mempengaruhi depresi selain social media addiction, karena hipotesis pada penelitian ini ditolak. Peneliti selanjutnya juga disarankan untuk menggunakan teknik probability sampling agar semua kelompok dari populasi bisa terwakili dan sampel yang didapatkan bisa lebih rata. Selain itu, jika peneliti selanjutnya ingin meneliti lebih dalam mengenai social comparison di Instagram, disarankan untuk meneliti dua jenis social comparison secara spesifik, yaitu upward social comparison dan downward social comparison. Karena sampai saat ini belum ada alat ukur yang mengukur upward social comparison dan downward social comparison, peneliti selanjutnya dapat menjadikan hal ini sebagai peluang dan mengembangkan alat ukur untuk kedua jenis dari social comparison tersebut.

\section{DAFTAR PUSTAKA}

Alfindra, M. F., \& Yahya, M. (2017). Motivasi mahasiswa bergabung dalam media sosial instagram. Jurnal Ilmiah Mahasiswa FISIP Unsyiah, 2(3), 72-81.
Andreassen, C. S., Pallesen, S., \& Griffiths, M. (2017). The relationship between addictive use of social media, narcississm, and self-esteem: Findings from a large national survey. Addictive Behavior, 64, 287-293.

doi:10.1016/j.addbeh.2016.03.006

Andreassen, C. S., Pallesen, S., \& Griffiths, M. (2017). The relationship between addictive use of social media, narcississm, and self-esteem: Findings from a large national survey. Addictive Behavior, 64, 287-293.

doi:10.1016/j.addbeh.2016.03.006

Andreassen, C. S., Torsheim, T., Brunborg, G. S., \& Pallesen, S. (2012). Development of facebook addiction scale. Psychological Reports, $\quad 110(2), \quad 501-517$. doi:10.2466/02.09.18.PR0.110.2.501-517

Arnett, J. J. (2014). Emerging adulthood: The winding road from the late teens through the twenties (2nd ed.). New York: Oxford University Press.

Baker, D. A., \& Algorta, G. P. (2016) the relationship between online social networking and depression: A systematic review of quantitative studies. Cyberpsychology, Behavior, and Social Networking, $\quad 19(11), \quad 1-11$. doi:10.1089/cyber.2016.0206

Beck, A. T., \& Alford, B. A. (2009). Depression: Causes and treatment (2nd ed.). Philadelphia: University of Pennsylvania Press.

Beck, A. T., Steer, R. A., \& Brown, G. K. (1996). BDI-II, beck depression inventory: Manual (2nd ed.). Boston: Harcour, Brace, and Company.

Beck, A. T., Steer, R. A., Ball, R., \& Ranieri, W. F. (1999). Dimensions of the beck depression inventory-ii in clinically depressed outpatients. Journal of Clinical Psychology, 55(1), 117-128. 
Brown, D. J., Ferris, D. L., Heller, D., \& Keeping, L. M. (2007). Antecedents and consequences of the frequency of upward and downward social comparisons at work. Organizational Behavior and Human Decision Processes, 102(1), 59-75. doi:10.1016/j.obhdp.2006.10.003

Budury, S., Fitriasari, A., Khamida. (2019). Penggunaan media sosial terhadap kejadian depresi, kecemasan, dan stres pada mahasiswa. Bali Medika Jurnal, 6(2), 214-217.

Choukas-Bradley, S., Nesi, J., Widman, L., \& Higgins, M. K. (2019). Camera-ready: Young women's appearance-related social media consciousness. Psychology of Popular Media Culture, 8(4), 473-481. doi: 10.1037/ppm0000196

Dailey, S. L., Howard, K., Roming, S. M. P., Ceballos, N., \& Grimes, T. (2020). A biopsychosocial approach to understanding social media addiction. Human Behavior and Emerging Technologies, 2(2), 158-167. doi:10.1002/hbe2.182

Darnon, C., Dompnier, B., \& Poortvliet, P. M. (2012). Achievement goals in educational contexts: A social psychology perspective. Social and Personality Compass, 6(10), 760-771. doi:10.1111/j.1751-9004.2012.00457.x

Donnelly, E., \& Kuss, D. J. (2016). Depression among users of social networking sites (SNSs): The role of SNS addiction and increased usage. Journal of Addiction and Preventive Medicine, 1(2), 1-6.

Festinger, L. (1954). A theory of social comparison process. Human Relation, 7(2), 117-140.

doi:10.1177/001872675400700202

Gaol, L. A. L., Mutiara, A. B., Saraswati, N. L., Rahmadini, R., \& Hilmah, M. A.
(2018). The relationship between social comparison and depressive symptoms among Indonesian instagram users. Advances in Social Science, Education and Humanities Research, 139, 130-137.

Garcia, S. M., Reese, Z. A., \& Tor, A. (2019). Social comparison before, during, and after the competition. In J. Suls, R. Collins, \& L. Wheelers (Eds.), Social comparison, judgement, and behavior (pp. 105-142). New York, NY: Oxford University Press.

Glaser, P., Liu, J. H., Hakim, M. A., Vilar, R., \& Zhang, R. (2018). Is social media use for networking positive or negative? Offline social capital and internet addiction as mediators for the relationship between social media use and mental health. New Zealand Journal of Psychology (Online), 47(3), 12-18.

Gibbons, F. X., \& Buunk, B. P. (1999). Individual differences in social comparison: Development of a scale of social orientation. Journal of Personality and Social Psychology, 76(1), 129-142.

Kartol, A., \& Gundogan, S. (2020). The mediating role of emotional intelligence in the relationship between the fear of missing out in social environtments (FoMO) and depression. European Journal of Educational Studies, 6(11), 116. doi:10.5281/zenodo.3613904

Kircaburun, K., \& Griffiths, M. D. (2018). instagram addiction and the big five personality: The mediating role of selfliking. Journal of Behavioral Addictions, 7(1), 158-170. doi: 10.1556/2006.7.2018.15

Li, J. B., Mo, P. K. H., Lau, J. T. F., Su, X. F., Zhang, X., Wu, A. M. S., Mai, J. C., \& Chen, Y. X. (2018). Online social networking addiction and depression: The result frm large scale prospective cohort study in Chinese adolescents. Journal of 
Behavioral Addictions, 7(3), 686-696. doi:10.1556/2006.7.2018.69

Lup, K., Trub, L., \& Rosenthal, L. (2015). instagram \#instasad?: Exploring associations among instagram use, depressive symptoms, negative social comparison, and strangers followed. Cyberpsychology, Behavior, and Social Networking, 18(5), 247-252. doi:10.1089/cyber.2014.0560

Meier, A., Gilbert, A., Borner, S., \& Possler, D. (2020). Instagram inspiration: How upward comparison on social network sites can contribute to well-being. Journal of Communication, 70(5), 721-743. doi:10.1093/joc/jqaa025

Muna, R. F., \& Astuti, T. P. (2014). Hubungan antara kontrol diri dengan kecenderungan kecanduan media sosial pada remaja akhir. Jurnal Empati, 3(4), 481-491.

NapoleonCat. (2020, Maret). Instagram users in Indonesia - March 2020. Dipetik April 26, 2020, dari NapoleonCat.com: https://napoleoncat.com/stats/instagramusers-in-indonesia/2020/03

Sheldon. P., \& Bryant, K. (2016). Instagram: Motives for its use and relationship to narcissism and contextual age. Computers in Human Behavior, 58, 89-97. doi:10.1016/j.chb.2015.12.059

Summers, J. J., Schallert, D. L., \& Ritter, P. M. (2003). The role of social comparison in students' perceptions of ability: An enrichd view of academic motivation in middle school students. Contemporary Educational Psychology, 28(4), 510-523. doi: 10.1016/S0361476X(02)00059-0

Wang, J. L., Wang, H. Z., Gaskin, J., \& Hawk, S. (2017). The mediating roles of upward social comparion and self-esteem and the moderating role of social comparison orientation in the association between social networking site usage and subjective well-being. Frontiers in Psychology, $\quad 8, \quad 1-9$. doi:10.3389/fpsyg.2017.00771

Wardani, A. S. (2017, Mei 20). Instagram sering bikin anak muda depresi ketimbang medsos lain. Dipetik April 28, 2020, dari Liputan6.com:

https://www.liputan6.com/tekno/read/2957 904/instagram-sering-bikin-anak-mudadepresi-ketimbang-medsos-lain

Sosiawan, E. A., \& Wibowo, R. (2018). Model dan pola computer mediated communication pengguna remaja instagram dan pembentukan budaya visual. Jurnal Ilmu Komunikasi, 16(2), 147-157.

Suls, J., Martin, R., \& Wheeler, L. (2002). Social comparison: Why, with whom, and with what effect?. Current Directions in Psychological Science, 11, 159-163. doi:10.1111/1467-8721.00191

Sumaryanti, I. U., Azzizah, S., Diantina, F. P., \& Nawangsih, E. (2020). Personality and social media addiction among college students. In W. Strielkowski, \& J. Cheng (Eds.), Advances in Social Science, Education and Humanities Research: Vol. 409. 2nd Social and Humaniora Research Symposium (pp. 376-379). Paris, Prancis: Atlantis Press. doi:10.2991/assehr.k.200225.079

$\mathrm{Wu}$, S. (2019). The relationship between social media use and depression in college students: A scoping review (Doctoral dissertation, UT Health). Retrieved from https://digitalcommons.library.tmc.edu/uth sph_dissertsopen/100 
Psychopreneur Journal, 2021, 5(1): 1-10

ISSN 2598-649X cetak / ISSN 2598-6503 online

Zhang, R. (2017). The stress-buffering effect of self-disclosure on facebook: An examination of stressful life events, social support, and mental health among college students. Computers in Human Behavior, 75 ,

527-537.

doi:10.1016/j.chb.2017.05.043 